\section{US genomics leader bows out from institute}

Francis Collins, the
geneticist who led the
US National Human
Genome Research
Institute (NHGRI)
in Bethesda,
Maryland, through
the completion of
the Human Genome
Project and the
dawn of the personal Francis Collins.
genomics era, has announced that he will leave his post on 1 August.

In a news conference last week, Collins said he has no concrete plans about his future and was leaving the NHGRI to explore posts "that would be very difficult to consider or discuss or pursue while continuing in my role as a federal employee". Many speculate that Collins could assume a leadership role in the next presidential administration, possibly as director of the National Institutes of Health or science adviser to the president. Collins also says that he would like to write a book about personal genomics for the public.

During his 15-year tenure, Collins led what many scientists see as a shift towards funding large-scale projects. He became known as a public face of the Human Genome Project and drew the wrath of some scientists for arguing that science and religious faith are compatible (see Nature 442, 114-115; 2006).

See Editorial, page 697.

\section{Merck scores victory in three Vioxx appeals}

Appeals courts in two US states last week overturned verdicts favouring plaintiffs who had sued Merck, the pharmaceutical giant, over its painkiller Vioxx (rofecoxib). The drug was taken off the market in 2004 after a study showed it doubled the risk of heart attacks and strokes.

In Texas, a three-judge panel reversed a \$26-million jury verdict in the first and most public Vioxx lawsuit. It said that lawyers for Carol Ernst had failed to prove that the drug caused the death of her husband in 2001 (see Nature 436, 1070; 2005). Ernst's lead attorney said they would appeal the decision.

The ruling came the same day that a New Jersey appeals court scuttled $\$ 9$ million in punitive damages awarded to John McDarby in 2006 - arguing that the law under which the money was awarded is trumped by the federal law under which the Food and Drug Administration approves drugs for market.

The reversals mean that, out of 16 Vioxx cases that have completed trials so far, only three have resulted in unqualified victories by plaintiffs. The bigger picture for the company and for tens of thousands of other plaintiffs remains largely unchanged because of a \$4.85-billion settlement agreed last November (see Nature 450, 324; 2007).

\section{Indian coral islands under threat from algae}

A dispute about non-native algae has broken out in India between beverage giant PepsiCo and the Central Salt \& Marine Chemicals Research Institute (CSMCRI), which is based in Bhavnagar, Gujarat.

Institute researchers originally imported the alga Kappaphycus alvarezii for research; in 2001 PepsiCo began cultivating it for the food thickener carrageenan in the Gulf of Mannar marine bioreserve, along India's southeastern coast. Reporting in Current Science last month, scientists from Thiagarajar College in Madurai say that corals fringing an island in the gulf are being smothered to death by the algae.

The CSMCRI suspects that the algae drifted into protected waters from PepsiCo's 